\title{
Direct and indirect association between environmental factors and fruit intake, mediation by psychosocial factors: the Pro Children study
}

\author{
Marianne Wind ${ }^{1}$, Saskia J te Velde ${ }^{2, *}$, Johannes Brug ${ }^{2}$, Camilla Sandvik ${ }^{1,3}$ and \\ Knut-Inge Klepp ${ }^{1}$ \\ 'Department of Nutrition, Institute for Basic Medical Sciences, University of Oslo, Blindern, Oslo, Norway: \\ ${ }^{2}$ Department of Epidemiology and Biostatistics, EMGO Institute for Health and Care Research, VU University \\ Medical Center, Van der Boechorststraat 7, 1081 BT, Amsterdam, The Netherlands: ${ }^{3}$ Faculty of Psychology, \\ Research Centre for Health Promotion, University of Bergen, Bergen, Norway
}

Submitted February 2009: Accepted May 2010

\begin{abstract}
Objectives: To explore direct associations between home and school availability of fruit and fruit intake, and the mediating role of attitude towards fruit, liking, perceived barriers and self-efficacy.

Design: Cross-sectional study.

Setting: Primary schools in nine European countries.

Subjects: Within the Pro Children study, data were collected on perceived home and school availability of fruit, psychosocial factors related to fruit intake and its frequency among 13305 11-year-old schoolchildren.

Results: Significant overall associations were found between child-reported home availability of fruit and fruit intake in all countries and in the total sample. School availability of fruit was associated with fruit intake in the pooled sample and in country-specific analyses in Sweden and the Netherlands. Liking (13·2-49·4\%) and self-efficacy $(14 \cdot 0-25 \cdot 1 \%)$ were the strongest mediators in the home availabilityfruit intake relationship, but there was also a direct association between home availability and fruit intake, except in Spain and the Netherlands. Mediating pathways of the school availability-fruit intake relationship could only be assessed for Norway, Sweden and the total sample. Attitude was a significant mediator in Norway $(80 \cdot 4 \%)$ and in Sweden $(25 \cdot 3 \%)$, while in the total sample also liking $(38 \cdot 7 \%)$ and self-efficacy $(23 \cdot 0 \%)$ were identified as significant mediators.

Conclusions: The association between home availability of fruit and fruit intake is at least partly mediated by personal factors such as liking and self-efficacy indicates that fruit intake is not a complete automatic or unconscious behaviour.
\end{abstract}

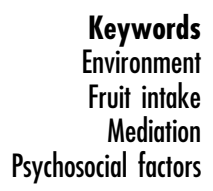

Environment

Mediation

Psychosocial factors
Several studies have shown that fruit and vegetable intake among European children and adolescents is lower than the international daily recommended intake levels ${ }^{(1,2)}$. Moreover, intake is declining among American adolescents $^{(3)}$ and in some European countries ${ }^{(4)}$, although a positive trend was found among English children between 2000 and $2005^{(5)}$. Regular intake of fruit and vegetables has been associated with lower risk of CVD, including obesity, hypertension and type 2 diabetes mellitus and some cancers ${ }^{(6-8)}$. On the other hand, a recent paper by $\mathrm{Newby}^{(9)}$ reported that there is no support for the proposition that any plant food intake is inversely correlated with adiposity among children. However, Newby also stated that the lack of evidence showing an association between plant-based diets and childhood obesity does not mean that such diets should not be encouraged. Plant foods are considered to be part of a healthy balanced diet, which in combination with physical activity, is recommended as important in weight management and prevention of unnecessary weight gain $^{(10)}$. Promoting fruit intake is considered a goal for the promotion of population health, especially among children and adolescents, since some studies have shown that fruit intake might track into adulthood ${ }^{(11-13)}$, and that preferences established early in life tend to be maintained during adulthood as well ${ }^{(14)}$. In order to promote children's intake of fruit and vegetables, insight into important mediating factors is necessary ${ }^{(15,16)}$. Mediating factors or mediators are variables that explain the association between the two variables or are in the pathway between two the variables.

Previous studies have shown associations between the reported intake of fruit and vegetables and environmental 
and psychosocial factors, including availability ${ }^{(17,18)}$, preferences for fruit, knowledge of the daily recommended intake levels, behavioural capability (skills) in determining healthy choices, outcome expectations ${ }^{(18)}$, self-efficacy ${ }^{(18,19)}$, preferences for fruit and vegetables ${ }^{(17)}$ and perceived parental influences ${ }^{(19)}$. Kratt et al. ${ }^{(18)}$ and Young et al. ${ }^{(19)}$ showed that the association between psychosocial factors and intake was moderated by availability, i.e. this association changed as the level of availability changed. Cullen et $a l^{(17)}$ suggested that preferences moderate the association between availability and intake. Based on these studies and a study by Jago et al., ${ }^{(20)}$ we could say that the exact mechanisms between availability and intake and the nature of this relationship with psychosocial factors are still unclear and that, to our knowledge, no other studies have explored the potential pathways in fruit availability at home or school and fruit intake relationship. The role of the environment is getting more attention in the social-ecological models ${ }^{(21)}$, and more research is needed regarding 'how' environments might affect behaviour ${ }^{(22,23)}$. The EnRG framework postulates that the environment influences behaviour both directly and indirectly ${ }^{(23)}$. Since children and adolescents may have less autonomy in making healthy dietary choices, environmental influences can have a direct influence on their intake. Such a direct influence reflects the automatic, unconscious influence of the environment on behaviour ${ }^{(24)}$. The indirect causal mechanism reflects the mediating role of behaviour-specific cognitions in the influence of the environment on behaviour ${ }^{(23)}$. Furthermore, the association between environmental factors and behaviour might differ by geographical and psychosocial factors. Within the European Pro Children study, data on intake of fruit and environmental and psychosocial factors have been collected among 13305 children from nine European countries. Therefore, the current study provided the opportunity to study potential mediating pathways between fruit availability at home and school and fruit intake. Results will contribute to unravelling the still unclear nature of the fruit availability-fruit intake relationship. In addition, the data also provided the opportunity to explore whether the same potential mediators are important across the nine countries. Therefore, the aim of the present study was to explore the associations between home and school availability of fruit and fruit intake, and the potential mediating role of four psychosocial factors in nine European countries.

\section{Method}

\section{Design and sample}

The study used data from the European Pro Children cross-sectional study on children's fruit and vegetable intake and potential environmental and psychosocial determinants ${ }^{(25)}$. The cross-sectional study involved nine European countries (Austria, Belgium, Denmark, Iceland, the Netherlands, Norway, Portugal, Spain and Sweden).
Data were collected during October-December 2003 involving national representative samples of schools in all countries with the exception of Austria (for Austria, the sample was representative for the Eastern region) and Belgium (for Belgium, the sample was representative for Flanders). Schools were used as the sampling unit, and from each country at least twenty schools were sampled and a minimum of 1300 eligible children were included. Participation rates ranged from $70 \%$ to $97 \%$, with Portugal (45\%) and the Netherlands (30\%) showing lower participation rates. The most frequent reason for schools not participating in the study were time constraints. Participating students completed a questionnaire in the classroom. Reasons for non-participation at the pupil level were not being present at the time of data collection, and were thus not related to specific reasons related to the project. Ethical approval was obtained from all relevant ethics committees in all countries before participation. Eleven-year-old children were recruited to the study, and a response rate of $90 \cdot 4 \%$ was reached in the participating schools; response rates ranged from $79 \cdot 7 \%$ to $98.4 \%$, with Portugal showing the highest rates and the Netherlands showing the lowest response rates. Mean age was $11 \cdot 4$ years (range: $8 \cdot 8-13 \cdot 8, \mathrm{SD}=0 \cdot 48 ; 79 \%$ of the children were born in 1992), and $50 \cdot 2 \%$ were boys. The final sample sizes varied from 1105 for the Netherlands to 2134 for Portugal, with a total sample size of 13305 students. A more detailed description of the Pro Children project, including the sampling and data collection procedure, is given elsewhere ${ }^{(1,25)}$. Owing to missing values, a maximum of 12200 children $(91.7 \%)$ were included in the analyses. Children were only included in the analyses when they had complete data on the predictor variable, the mediators as well as the outcome variable. Boys were more likely to have at least one missing variable $(\mathrm{OR}=1 \cdot 49$, 95\% CI $1 \cdot 29,2 \cdot 09)$.

\section{Measures}

A self-reported questionnaire was developed to measure fruit and vegetable intake, and the related environmental and psychosocial factors. The development of the questionnaire was based on theoretical models ${ }^{(25)}$, a literature review $^{(26)}$, focus group interviews with children ${ }^{(27)}$, individual interviews with parents and school staff and thorough pre-testing ${ }^{(28,29)}$. Fruit intake was assessed by an FFQ: 'How often do you usually eat fresh fruit', with an 8-point answer scale ranging from never $(0)$ to every day more than twice a day (7). A separate validation study showed reasonable-togood test-retest reliability (Spearman $r$ from $0 \cdot 47$ to $0 \cdot 77$ ) and, in general, adequate validity comparing the food frequency questions with $7 \mathrm{~d}$ food records (Spearman $r$ from 0.43 to 0.51$)^{(28)}$. As part of the demographics questionnaire, gender and age (calculated based on the year and month of birth) were included in the present study.

Perceived availability of fruit at home and at school was assessed using a bipolar 5-point scale ranging from 'yes always' to 'never'. All four psychosocial factors (i.e. attitudes 
Table 1 Constructs and items of the Pro Children questionnaire

\begin{tabular}{|c|c|c|c|}
\hline Constructs & Cronbach's $\alpha$ & Items & Response categories \\
\hline Fruit intake & $\mathrm{N} / \mathrm{A}$ & How often do you usually eat fruit? & $\begin{array}{l}\text { (0) Never, (1) }<1 \mathrm{~d} / \text { week, (2) } 1 \mathrm{~d} / \text { week, (3) } \\
2-4 \mathrm{~d} / \text { week, (4) 5-6 d/week, (5) every day, } \\
\text { once a day, (6) every day, twice a day and } \\
\text { (7) every day more than twice a day }\end{array}$ \\
\hline $\begin{array}{l}\text { Perceived availability } \\
\text { at home }\end{array}$ & $\mathrm{N} / \mathrm{A}$ & $\begin{array}{l}\text { Are there usually different kinds of fruit } \\
\text { available at your home? }\end{array}$ & 5-point scale from 2 (yes, always) to -2 (never) \\
\hline $\begin{array}{l}\text { Perceived availability } \\
\text { at school }\end{array}$ & $\mathrm{N} / \mathrm{A}$ & $\begin{array}{l}\text { Can you get fruit at school either by } \\
\text { buying it or getting it or free? }\end{array}$ & 5-point scale from 2 (yes, always) to -2 (never) \\
\hline Attitude & $0 \cdot 73$ & $\begin{array}{l}\text { Eating fruit every day makes me feel } \\
\text { good } \\
\text { Eating fruit every day gives me more } \\
\text { energy }\end{array}$ & $\begin{array}{l}\text { 5-point scale from } 2 \text { (I fully agree) to }-2 \text { (I fully } \\
\text { disagree) }\end{array}$ \\
\hline Liking & $0 \cdot 68$ & $\begin{array}{l}\text { I like to eat fruit every day } \\
\text { Fruit tastes good }\end{array}$ & $\begin{array}{l}\text { 5-point scale from } 2 \text { (I fully agree) to }-2 \text { (I fully } \\
\text { disagree) }\end{array}$ \\
\hline Self-efficacy & $0 \cdot 39$ & $\begin{array}{l}\text { It is difficult for me to eat fruit every day } \\
\text { If I decide to eat fruit every day, I can } \\
\text { do it }\end{array}$ & $\begin{array}{l}\text { 5-point scale from } 2 \text { (I fully agree) to }-2 \text { (I fully } \\
\text { disagree) }\end{array}$ \\
\hline Perceived barriers & $0 \cdot 72$ & $\begin{array}{l}\text { I do not eat fruit because: } \\
\text { - It takes too much time to eat } \\
\text { - I want to eat something else } \\
\text { (e.g. sweets) } \\
\text { - My fingers get greasy when I eat it } \\
\text { - It gets squeezed in the school bag }\end{array}$ & $\begin{array}{l}\text { 5-point scale from } 2 \text { (I fully agree) to }-2 \text { (I fully } \\
\text { disagree) }\end{array}$ \\
\hline
\end{tabular}

$\mathrm{N} / \mathrm{A}$, not applicable.

towards fruit, liking of fruit, self-efficacy for eating fruit and barriers to prevent eating fruit) were assessed using a bipolar 5-point scale ranging from 'fully agree' to 'fully disagree'. Before the analyses, composite scores were calculated for these four factors as the mean of two or four items. Intra-class correlations in the test-retest reliability analyses of these factors were $0 \cdot 58-0 \cdot 74$, while Cronbach $\alpha$ values ranged from 0.42 for self-efficacy, 0.53 for perceived barriers, 0.61 for attitude to 0.70 for liking, respectively (see De Bourdeaudhuij et al. ${ }^{(29)}$ for detailed information on the psychometrics and also see Table 1 for a more detailed description of the measures).

\section{Analyses}

A series of multiple regression analyses were performed to identify mediation of the association between fruit availability and fruit intake by the individual-level psychosocial factors: attitude, liking, barriers and self-efficacy. Basically, suggestions from MacKinnon ${ }^{(30)}$ were followed. First, the overall effect (path c) of the predictor variable ( $X$, fruit availability) on the outcome variable fruit intake $(Y)$ was assessed (see Fig. 1). Subsequently, associations between fruit availability $(X)$ and the mediators $\left(M_{i}\right)$ (paths a) were assessed. Then, associations between the mediators $\left(M_{i}\right)$ and the outcome variable fruit intake $(Y$ ) were assessed (paths b) in a multiple regression model that was adjusted for the predictor variable $(X)$. Those mediators that were significantly associated with both the predictor variable and the outcome variable were selected for the final multiple mediation model. The 'mediated effect' was calculated following the 'product-of-coefficients' method ${ }^{(30)}$, i.e. by multiplying the $\alpha$-coefficient by the $\beta$-coefficient. The $\beta$-coefficients



Fig. 1 The mediation model for the association between availability and fruit intake. $X$, predictor variable; $Y$, outcome variable; $M_{1}$, mediator variable; $a_{\mathrm{i}}$, association between predictor variable $(X)$ and potential mediator $\left(M_{1}\right) ; b_{i}$, association between predictor variable $(X)$ and outcome variable $(Y) ; c^{\prime}$, direct effect (unnamed) of predictor variable $(X)$ on outcome variable $(Y)$

were derived from the final multiple mediation model including only the selected mediators. Standard errors for the mediated effect were calculated as:

$$
\left.\mathrm{SE}_{a \times b}=\sqrt{(} a^{2} \times \mathrm{SE} b^{2}+b^{2} \times \mathrm{SE} a^{2}\right) \quad \text { Equation (1) }
$$

In case more than one mediator was significantly associated with both the predictor variable and the outcome variable, total mediated effect by two or more mediator variables was calculated by summing the mediated effects of the individual mediators derived from a multiple regression equation $\left(\sum\left(a_{i} \times b_{i}\right)\right)$. Standard errors for the total mediated effects were calculated according to the following equation:

$$
\begin{aligned}
\mathrm{SE}_{\Sigma a_{i} \times b_{i}}= & \sqrt{(} a_{1}^{2} \times \mathrm{SE} b_{1}^{2}+b_{1}^{2} \times \mathrm{SE} a_{1}^{2}+a_{2}^{2} \times \mathrm{SE}_{2}^{2} \\
& +b_{2}^{2} \times \mathrm{SE} a_{2}^{2}+\ldots+2 \times a_{1} \times a_{2} \\
& \left.\times \mathrm{COV}_{b_{1} b_{2}}+\ldots\right)
\end{aligned}
$$


Table 2 Total effects (path c) of fruit availability at home and school on fruit intake for all nine countries and the total sample

\begin{tabular}{|c|c|c|c|c|c|c|}
\hline \multirow[b]{3}{*}{ Country } & \multicolumn{6}{|c|}{ Total effect* } \\
\hline & \multicolumn{3}{|c|}{ Home availability } & \multicolumn{3}{|c|}{ School availability } \\
\hline & $n$ & OR & $95 \% \mathrm{Cl}$ & $n$ & OR & $95 \% \mathrm{Cl}$ \\
\hline Norway & 1116 & 0.285 & $0.212,0.358$ & 1104 & 0.014 & $-0.023,0.052$ \\
\hline Spain & 1268 & 0.281 & $0.203,0.359$ & 1271 & 0.014 & $-0.023,0.050$ \\
\hline Iceland & 1156 & 0.305 & $0.236,0.374$ & 1143 & 0.007 & $-0.025,0.039$ \\
\hline Denmark & 1809 & 0.476 & $0.409,0.543$ & 1822 & 0.022 & $-0.008,0.052$ \\
\hline Portugal & 2075 & 0.199 & $0 \cdot 134,0.264$ & 2077 & 0.009 & $-0.016,0.035$ \\
\hline Austria & 1667 & 0.324 & $0.246,0.402$ & 1646 & -0.001 & $-0.031,0.029$ \\
\hline The Netherlands & 1085 & 0.237 & $0 \cdot 161,0.313$ & 1071 & 0.082 & $0.001,0.162$ \\
\hline Sweden & 1368 & 0.365 & $0.292,0.438$ & 1358 & 0.049 & $0.013,0.086$ \\
\hline Belgium & 1336 & 0.261 & $0.200,0.322$ & 1317 & 0.010 & $-0.020,0.041$ \\
\hline Total & 12880 & 0.307 & $0.284,0.331$ & 12809 & 0.017 & $0.006,0.028$ \\
\hline
\end{tabular}

${ }^{*}$ Assessed by regression analyses adjusted for age and gender and the nested design.

Bold values represent significant association.

In equations 1 and 2, ' $a$ ' stands for the regression coefficient in path $a$, ' $b$ ' stands for the regression coefficient in path $\mathrm{b}$, and the numbering reflects the different mediators. $\mathrm{COV}_{b_{1} b_{2}}$ stands for the covariance between the two $\mathrm{b}$ estimates and the $2 \times a_{1} \times a_{1} \times \mathrm{COV}_{b_{1} b_{2}}$ is repeated for all pairs of coefficients in the multiple mediator model.

The proportion of the total effect that was mediated by the mediator(s) was calculated by dividing the mediated effect by the total effect $\left(c^{\prime}+\sum\left(a_{i} \times b_{i}\right)\right.$ and multiplying by $100 \%$. This proportion was not calculated in case of a non-significant mediation effect.

A significant overall relationship between the predictor variable and the outcome variable was not a requirement to continue the mediation analyses, since absence of an overall relationship may be due to suppression effects ${ }^{(30,31)}$.

In the mediation analyses, we used the term 'effect' next to 'association' to be consistent with MacKinnon's terminology, even though we realize that the analyses are crosssectional and no conclusions can be drawn in the direction of causality. All analyses were corrected for gender and age, and conducted per country and for the total sample. Further, all analyses took into account the nested design of the study, i.e. pupils nested within schools (and within countries), by using mixed-effects REML regression analyses in the STATA/IC statistical software package version 10·1 (StataCorp LP, College Station, TX, USA). Descriptive statistics were provided in the Statistical Package for the Social Sciences statistical software package version $15 \cdot 0$ (SPSS Inc., Chicago, IL, USA). For associations, the significance level was set at $P<0 \cdot 05$.

\section{Results}

\section{Associations of bome and school availability with fruit intake}

Significant overall associations (path c) were found for child-reported home availability of fruit with childreported fruit intake in all countries (c varied between
0.199 and $0 \cdot 476)$ and for the total sample (c $=0.332$; 95\% CI 0.307, 0.357; see Table 2). School availability as reported by the child was significantly associated with intake in two countries (the Netherlands: $\mathrm{c}=0.081 ; 95 \%$ CI $0 \cdot 001,0 \cdot 161$; Sweden: $c=0 \cdot 049,95 \%$ CI $0 \cdot 014,0 \cdot 084)$ and in the total sample $(c=0 \cdot 017 ; 95 \%$ CI 0.006, 0.028).

Table 3 shows the association between home and school availability with the four potential mediators: attitude, liking, self-efficacy and barriers (path a) for the nine countries separately and for the total sample. As can be seen, home availability was significantly associated with all the four potential mediators. Positive associations were observed for home availability and attitude towards fruit intake, liking of fruit and self-efficacy for eating fruit, while higher home availability was inversely associated with perceived barriers to eating fruit.

In the total sample, school availability was significantly associated with three potential mediators: attitude towards fruit intake, liking of fruit and self-efficacy for eating fruit. School availability was positively associated with attitude towards fruit in five countries (Norway, Spain, Denmark, Austria and Sweden), while school availability was associated with liking in only two countries (Spain and Denmark). In none of the countries was school availability associated with self-efficacy, and perceived barriers were only significantly associated with school availability in Denmark.

\section{Associations between potential mediators and fruit intake}

Table 3 also shows the associations between the potential mediators and the outcome variable fruit intake (path b). In the total sample liking, self-efficacy and perceived barriers were significantly associated with fruit intake while adjusting for home availability, whereas attitude towards fruit intake was not. Nevertheless, a significant pathway between attitude and fruit intake was observed in five countries (Iceland, Denmark, Austria, the Netherlands and Belgium). In accordance with the findings in the 
Table 3 Associations between availability, and the four potential mediators, and associations between the four potential mediators and intake, for all countries and the total sample

\begin{tabular}{|c|c|c|c|c|c|c|c|c|c|}
\hline & \multirow[b]{4}{*}{ Potential mediator } & \multicolumn{4}{|c|}{ Association between predictor and potential mediators (path $a)^{*}$} & \multicolumn{4}{|c|}{ Association potential mediators and fruit intake $(\text { path } b)^{\star}+$} \\
\hline & & \multicolumn{2}{|c|}{ Home availability } & \multicolumn{2}{|c|}{ School availability } & \multicolumn{2}{|c|}{ Home availability } & \multicolumn{2}{|c|}{ School availability } \\
\hline & & \multicolumn{2}{|c|}{ Estimate } & \multicolumn{2}{|c|}{ Estimate } & \multicolumn{2}{|c|}{ Estimate } & \multicolumn{2}{|c|}{ Estimate } \\
\hline & & OR & $95 \% \mathrm{Cl}$ & OR & $95 \% \mathrm{Cl}$ & OR & $95 \% \mathrm{Cl}$ & OR & $95 \% \mathrm{Cl}$ \\
\hline \multirow{4}{*}{ Norway } & Attitude & 0.235 & $0.161,0.309$ & 0.008 & $-0.026,0.042$ & 0.062 & $-0.002,0.127$ & 0.075 & $0 \cdot 010,0 \cdot 140$ \\
\hline & Liking & 0.263 & $0 \cdot 202,0.324$ & -0.001 & $-0.026,0.024$ & 0.255 & $0.169,0.341$ & 0.269 & $0.183,0.356$ \\
\hline & Self-efficacy & 0.341 & $0.265,0.417$ & 0.010 & $-0.024,0.044$ & $0 \cdot 114$ & $0.056,0.172$ & $0 \cdot 132$ & $0.073,0.190$ \\
\hline & Barriers & -0.256 & $-0.332,-0.180$ & -0.003 & $-0.035,0.030$ & -0.037 & $-0.097,0.023$ & 0.031 & $-0 \cdot 108,0.013$ \\
\hline \multirow[t]{4}{*}{ Spain } & Attitude & 0.368 & $0.304,0.432$ & 0.037 & $0.007,0.068$ & 0.035 & $-0.036,0.106$ & 0.041 & $-0.030,0.112$ \\
\hline & Liking & 0.506 & $0.431,0.581$ & 0.037 & $0.003,0.071$ & 0.202 & $0 \cdot 134,0.124$ & 0.212 & $0.144,0.280$ \\
\hline & Self-efficacy & 0.436 & $0.349,0.522$ & 0.013 & $-0.025,0.051$ & $0 \cdot 156$ & $0.098,0.214$ & $0 \cdot 154$ & $0.096,0.212$ \\
\hline & Barriers & -0.266 & $-0.341,-0.190$ & 0.007 & $-0.027,0.042$ & $-0 \cdot 106$ & $-0.165,-0.046$ & -0.109 & $-0.169,-0.050$ \\
\hline \multirow[t]{4}{*}{ Iceland } & Attitude & $0 \cdot 310$ & $0.240,0.380$ & 0.022 & $-0.011,0.055$ & $0 \cdot 110$ & $0.044,0.176$ & $0 \cdot 120$ & $0.053,0.186$ \\
\hline & Liking & 0.312 & $0.253,0.371$ & 0.027 & $-0.001,0.055$ & $0 \cdot 114$ & $0.028,0.200$ & $0 \cdot 129$ & $0.042,0.216$ \\
\hline & Self-efficacy & 0.412 & $0.340,0.484$ & 0.016 & $-0.018,0.049$ & $0 \cdot 169$ & $0 \cdot 110,0.228$ & $0 \cdot 194$ & $0.135,0.253$ \\
\hline & Barriers & $-0 \cdot 261$ & $-0.319,-0.203$ & 0.006 & $-0.021,0.033$ & -0.012 & $-0.085,0.062$ & -0.033 & $-0.107,0.041$ \\
\hline \multirow{4}{*}{ Denmark } & Attitude & $0 \cdot 401$ & $0.343,0.459$ & 0.048 & $0.021,0.075$ & 0.098 & $0.040,0.156$ & $0 \cdot 116$ & $0.059,0.174$ \\
\hline & Liking & 0.458 & $0.405,0.511$ & 0.039 & $0.018,0.061$ & $0 \cdot 201$ & $0.129,0.274$ & 0.235 & $0.163,0.306$ \\
\hline & Self-efficacy & 0.469 & $0.409,0.530$ & 0.051 & $0.028,0.073$ & 0.204 & $0 \cdot 147,0.260$ & 0.230 & $0.173,0.287$ \\
\hline & Barriers & -0.342 & $-0.396,-0.289$ & -0.026 & $-0.047,-0.005$ & -0.041 & $-0.099,0.016$ & -0.061 & $-0.118,-0.004$ \\
\hline \multirow[t]{4}{*}{ Portugal } & Attitude & $0 \cdot 141$ & $0.096,0.185$ & 0.009 & $-0.009,0.026$ & -0.003 & $-0.067,0.061$ & 0.004 & $-0.060,0.068$ \\
\hline & Liking & 0.246 & $0 \cdot 200,0 \cdot 291$ & -0.0002 & $-0.017,0.017$ & $0 \cdot 391$ & $0.323,0.459$ & 0.397 & $0.330,0.464$ \\
\hline & Self-efficacy & 0.252 & $0 \cdot 191,0 \cdot 313$ & 0.004 & $-0.019,0.027$ & $0 \cdot 138$ & $0 \cdot 090,0 \cdot 186$ & 0.143 & $0 \cdot 095,0.191$ \\
\hline & Barriers & $-0 \cdot 212$ & $-0.269,-0.155$ & -0.016 & $-0.039,0.006$ & -0.016 & $-0.065,0.034$ & -0.022 & $-0.071,0.027$ \\
\hline \multirow{4}{*}{ Australia } & Attitude & 0.342 & $0.276,0.409$ & 0.026 & $0.001,0.050$ & 0.078 & $0 \cdot 017,0.140$ & 0.085 & $0.023,0.147$ \\
\hline & Liking & 0.352 & $0.286,0.418$ & 0.021 & $-0.002,0.043$ & 0.224 & $0.154,0.293$ & 0.235 & $0 \cdot 165,0.306$ \\
\hline & Self-efficacy & 0.389 & $0.313,0.464$ & 0.009 & $-0.018,0.036$ & $0 \cdot 160$ & $0 \cdot 106,0.213$ & $0 \cdot 165$ & $0 \cdot 110,0.219$ \\
\hline & Barriers & $-0 \cdot 381$ & $-0.449,-0.313$ & -0.021 & $-0.047,0.005$ & $-0 \cdot 120$ & $-0.179,-0.060$ & -0.135 & $-0.195,-0.076$ \\
\hline \multirow[t]{4}{*}{ The Netherlands } & Attitude & $0 \cdot 164$ & $0.065,0.264$ & 0.090 & $-0.004,0.183$ & 0.069 & $0.023,0.115$ & 0.072 & $0.026,0.117$ \\
\hline & Liking & 0.391 & $0.304,0.479$ & 0.052 & $-0.031,0.134$ & 0.212 & $0 \cdot 153,0.270$ & 0.214 & $0.156,0.272$ \\
\hline & Self-efficacy & 0.391 & $0.285,0.497$ & 0.009 & $-0.092,0.111$ & $0 \cdot 150$ & $0.106,0.195$ & $0 \cdot 153$ & $0 \cdot 109,0 \cdot 198$ \\
\hline & Barriers & -0.232 & $-0.298,-0.165$ & -0.027 & $-0.090,0.037$ & -0.069 & $-0.136,-0.002$ & -0.073 & $-0.140,-0.006$ \\
\hline \multirow[t]{4}{*}{ Sweden } & Attitude & 0.375 & $0.304,0.447$ & 0.043 & $0.009,0.078$ & 0.043 & $-0.016,0.102$ & 0.066 & $0.007,0.126$ \\
\hline & Liking & 0.390 & $0.326,0.454$ & 0.010 & $-0.019,0.039$ & $0 \cdot 247$ & $0.174,0.321$ & 0.265 & $0.190,0.339$ \\
\hline & Self-efficacy & 0.493 & $0.417,0.570$ & 0.015 & $-0.021,0.051$ & $0 \cdot 175$ & $0.119,0.231$ & $0 \cdot 189$ & $0.133,0.245$ \\
\hline & Barriers & -0.230 & $-0.288,-0.173$ & 0.022 & $-0.005,0.049$ & -0.009 & $-0.077,0.059$ & -0.025 & $-0.093,0.042$ \\
\hline \multirow[t]{4}{*}{ Belgium } & Attitude & 0.208 & $0.147,0.269$ & -0.011 & $-0.044,0.021$ & 0.074 & $0 \cdot 018,0.129$ & 0.077 & $0.020,0.133$ \\
\hline & Liking & 0.303 & $0.244,0.363$ & 0.016 & $-0.011,0.043$ & 0.235 & $0.172,0.300$ & 0.242 & $0.177,0.306$ \\
\hline & Self-efficacy & 0.396 & $0.324,0.469$ & 0.012 & $-0.026,0.049$ & 0.119 & $0.070,0.168$ & 0.130 & $0.081,0.179$ \\
\hline & Barriers & -0.285 & $-0.341,-0.230$ & -0.007 & $-0.035,0.021$ & $-0 \cdot 103$ & $-0.164,-0.043$ & -0.116 & $-0.176,-0.055$ \\
\hline \multirow[t]{4}{*}{ Total } & Attitude & 0.283 & $0.261,0.305$ & 0.023 & $0.014,0.033$ & 0.065 & $0.044,0.085$ & 0.075 & $0.055,0.095$ \\
\hline & Liking & 0.353 & $0.333,0.374$ & 0.019 & $0.011,0.028$ & $0 \cdot 240$ & $0.216,0.264$ & 0.253 & $0.229,0.277$ \\
\hline & Self-efficacy & 0.393 & $0.333,0.374$ & 0.018 & $0.007,0.028$ & $0 \cdot 155$ & $0.137,0.173$ & $0 \cdot 165$ & $0 \cdot 147,0.183$ \\
\hline & Barriers & -0.276 & $-0.297,-0.255$ & -0.008 & $-0.017,0.001$ & -0.058 & $-0.078,-0.038$ & -0.069 & $-0.090,-0.049$ \\
\hline
\end{tabular}

${ }^{*}$ Adjusted for each other and adjusted for predictor variable $(X)$.

tAdjusted for gender and age and nested design. 
total sample, significant pathways between liking and fruit intake and between self-efficacy and fruit intake were found in all nine countries. Perceived barriers for eating fruit adjusted for home availability were significantly associated with intake in four countries (Spain, Austria, the Netherlands and Belgium).

Adjusted for school availability, all four potential mediators were significantly associated with fruit intake in the total sample. In line with this, in all nine countries separately liking and self-efficacy adjusted for school availability were significantly associated with fruit intake and attitude was significantly associated with fruit intake in seven countries (but not in Norway and Spain). Perceived barriers adjusted for school availability of fruit were associated with fruit intake in five countries (Spain, Denmark, Austria, the Netherlands and Belgium).

\section{Mediated effects, proportions mediated and direct effects}

Mediation effects (product of coefficients, $a \times b$ ) were calculated in multiple mediator models for those mediators that showed a significant association with the predictor variable (home or school availability) and with the outcome variable adjusted for the predictor variable. Table 4 shows the results for home availability as the predictor variable and Table 5 for the findings with school availability as the predictor variable.

In the total sample attitude, liking, self-efficacy and perceived barriers were all significant mediators in the relationship between home availability of fruit and fruit intake. Liking and self-efficacy came out as the strongest mediators, explaining $27 \cdot 7 \%$ and $19.9 \%$, respectively, of the relationship. All four mediators explained $58 \cdot 8 \%$ of the association, but home availability had also a direct effect on fruit intake, as shown by the significant $c^{\prime}$ pathway $\left(c^{\prime}=0 \cdot 126 ; 95 \%\right.$ CI 0.0284, 0.331). Liking and self-efficacy were also the strongest mediators in all countries separately, as shown by the proportion mediated varying between $13 \cdot 2 \%$ and $49 \cdot 4 \%$ for liking and between $14 \cdot 0 \%$ and $25 \cdot 1 \%$ for self-efficacy. Attitude was a significant mediator in five countries (Iceland, Denmark, Austria, the Netherlands and Belgium) explaining between $4.9 \%$ and $11.6 \%$ of the total effect. Finally, perceived barriers were found to be a significant mediator in four countries (Spain, Austria, the Netherlands and Belgium), explaining between $6 \cdot 8 \%$ and $14 \cdot 1 \%$ of the total effect of home availability on fruit intake.

In most countries, home availability was also directly associated with fruit intake, as shown in the last column of Table 4. Only in Spain and the Netherlands was the relationship completely mediated by the included mediators.

Regarding the relationship between school availability and fruit intake, this association appeared to be completely mediated by the three mediators when considering the total sample. Again, liking and self-efficacy came out as the strongest mediators, explaining $38.7 \%$ and
$23 \cdot 0 \%$, respectively, of the total association. There was no significant direct association of school availability with fruit intake. Regardless of an existing overall relationship between school availability of fruit and fruit intake, mediation analyses were conducted for all countries separately and the results are shown in Table 5.

In four countries, Iceland, Portugal, the Netherlands and Belgium, no mediating pathways were found and in none of the countries was a direct association of school availability of fruit with fruit intake observed. Attitude was a significant mediator in four countries (Norway, Denmark, Austria and Sweden) and liking was a significant mediator in two countries (Spain and Denmark). In addition, in Denmark self-efficacy was the strongest mediator between school availability of fruit and fruit intake. Perceived barriers appeared not to be a mediator in the relationship between school availability of fruit and fruit intake.

\section{Discussion}

Previous research showed that fruit intake of schoolchildren is associated with both environmental and psychosocial factors, indicating that interventions should be addressing both the environment and the individual ${ }^{(26,32)}$. Changing cognitions would, however, be inefficient when the relationship between availability and intake is not cognitively mediated ${ }^{(23)}$. Mediation analyses help to gain more insight into 'how' the environment may affect behaviour $^{(15,16,22)}$. In the present study, we explored the complex relationship between perceived availability, i.e. a presumed important physical environmental determinant, and fruit intake of schoolchildren in Europe and the possible mediating role of individual-level factors. The present study suggests that home availability of fruit does have a direct association with fruit intake in most countries and is at least partly mediated by individual-level mediators in all countries. The observed associations were mainly mediated by liking and self-efficacy for eating fruit, indicating that fruit intake is not a completely unconscious or automatic behaviour.

Liking and self-efficacy were significant mediators in all countries, suggesting that this mediating pathway was not influenced by country differences in, e.g. socio-cultural environments and/or school environmental factors.

School availability of fruit was significantly associated with self-reported fruit intake in the total sample and in the Netherlands and Sweden. In the Dutch case, this association was not mediated by the variables included in the present study. It may be that other variables explain the association, or that fruit intake is indeed directly influenced by school availability. In Sweden, the attitude towards fruit intake could explain about $25 \%$ of the association, suggesting that a higher availability of fruit at school may positively influence attitude, which in turn influences fruit intake. From the analyses in the total 
Table 4 Mediated effects $(a \times b)$, proportion mediated $(a \times b / c)$ and direct effects (path $\left.c^{\prime}\right)$ of fruit availability at home on fruit intake in the final model in nine European countries

\begin{tabular}{|c|c|c|c|c|c|c|c|c|}
\hline \multirow[b]{2}{*}{ Country } & \multirow[b]{2}{*}{ Mediator } & \multicolumn{2}{|c|}{$\begin{array}{l}\beta \text {-Coefficient in final mediation } \\
\text { model }\end{array}$} & \multicolumn{2}{|c|}{ Mediated effect $(a \times b)$} & \multirow{2}{*}{$\begin{array}{c}\text { Proportion } \\
\text { mediated }\end{array}$} & \multicolumn{2}{|c|}{$\begin{array}{l}\text { Direct effect of home availability } \\
\text { on fruit intake }\left(c^{\prime}\right)\end{array}$} \\
\hline & & $\mathrm{OR}^{*}$ & $95 \% \mathrm{Cl}$ & OR & $95 \% \mathrm{Cl}$ & & $\mathrm{OR}^{*}$ & $95 \% \mathrm{Cl}$ \\
\hline \multirow[t]{3}{*}{ Norway } & Liking & 0.308 & $0.235,0.381$ & 0.081 & $0.054,0.108$ & $28 \cdot 2$ & & \\
\hline & Self-efficacy & $0 \cdot 118$ & $0.061,0.175$ & 0.040 & $0.019,0.062$ & $14 \cdot 0$ & & \\
\hline & Liking and self-efficacy & & & $0 \cdot 121$ & $0.091,0.151$ & $42 \cdot 2$ & $0 \cdot 166$ & $0.093,0.239$ \\
\hline \multirow{4}{*}{ Spain } & Liking & $0 \cdot 213$ & $0.148,0.278$ & $0 \cdot 108$ & $0.071,0.145$ & $35 \cdot 3$ & & \\
\hline & Self-efficacy & $0 \cdot 156$ & $0.098,0.214$ & 0.068 & $0.040,0.097$ & $22 \cdot 3$ & & \\
\hline & Perceived barriers & $-0 \cdot 109$ & $-0.168,-0.050$ & 0.029 & $0.011,0.047$ & $9 \cdot 5$ & & \\
\hline & Liking, self-efficacy and perceived barriers & & & 0.205 & $0.166,0.244$ & $77 \cdot 2$ & 0.060 & $-0.022,0 \cdot 143$ \\
\hline \multirow[t]{4}{*}{ Iceland } & Attitude & 0.113 & $0.047,0.179$ & 0.035 & $0.013,0.057$ & $11 \cdot 6$ & & \\
\hline & Liking & 0.128 & $0.045,0.210$ & 0.040 & $0.013,0.066$ & $13 \cdot 2$ & & \\
\hline & Self-efficacy & $0 \cdot 163$ & $0 \cdot 105,0 \cdot 220$ & 0.067 & $0.041,0.093$ & $22 \cdot 2$ & & \\
\hline & Attitude, liking and self-efficacy & & & $0 \cdot 142$ & $0.112,0.172$ & $46 \cdot \overline{9}$ & 0.160 & $0.090,0.231$ \\
\hline \multirow{4}{*}{ Denmark } & Attitude & $0 \cdot 100$ & $0.043,0.158$ & 0.040 & $0.016,0.064$ & $8 \cdot 5$ & & \\
\hline & Liking & $0 \cdot 212$ & $0.141,0.282$ & 0.097 & $0.063,0.131$ & $20 \cdot 6$ & & \\
\hline & Self-efficacy & 0.209 & $0.153,0.264$ & 0.098 & $0.069,0.127$ & $20 \cdot 8$ & & \\
\hline & Attitude, liking and self-efficacy & & & 0.235 & $0.203,0.268$ & $49 \cdot 9$ & 0.236 & $0.169,0.303$ \\
\hline \multirow{3}{*}{ Portugal } & Liking & 0.397 & $0.334,0.460$ & 0.097 & $0.074,0.121$ & $49 \cdot 4$ & & \\
\hline & Self-efficacy & $0 \cdot 136$ & $0.089,0.182$ & 0.034 & $0.020,0.049$ & $17 \cdot 3$ & & \\
\hline & Liking and self-efficacy & & & $0 \cdot 132$ & $0 \cdot 107,0 \cdot 157$ & $66 \cdot 7$ & 0.066 & $0.003,0.128$ \\
\hline \multirow{5}{*}{ Australia } & Attitude & 0.079 & $0.017,0.140$ & 0.027 & $0.005,0.049$ & $8 \cdot 3$ & & \\
\hline & Liking & 0.224 & $0.154,0.293$ & 0.079 & $0.050,0.107$ & $24 \cdot 3$ & & \\
\hline & Self-efficacy & $0 \cdot 160$ & $0 \cdot 106,0.213$ & 0.062 & $0.038,0.086$ & $19 \cdot 1$ & & \\
\hline & Perceived barriers & $-0 \cdot 120$ & $-0.179,-0.060$ & 0.046 & $0.022,0.070$ & $14 \cdot 1$ & & \\
\hline & Attitude, liking, self-efficacy and perceived barriers & & & 0.213 & $0 \cdot 177,0 \cdot 250$ & $65 \cdot 8$ & $0 \cdot 111$ & $0.033,0.189$ \\
\hline \multirow[t]{5}{*}{ The Netherlands } & Attitude & 0.069 & $0.024,0.115$ & 0.011 & $0.001,0.022$ & 4.9 & & \\
\hline & Liking & $0 \cdot 212$ & $0 \cdot 153,0.270$ & 0.083 & $0.053,0.112$ & $35 \cdot 4$ & & \\
\hline & Self-efficacy & $0 \cdot 150$ & $0.106,0.195$ & 0.059 & $0.035,0.082$ & $25 \cdot 1$ & & \\
\hline & Perceived barriers & -0.069 & $-0.136,-0.002$ & 0.016 & $-0.0002,0.032$ & $6 \cdot 8$ & & \\
\hline & Attitude, liking, self-efficacy, perceived barriers & & & $0 \cdot 169$ & $0.133,0.205$ & $72 \cdot 2$ & 0.065 & $-0.008,0.312$ \\
\hline \multirow[t]{3}{*}{ Sweden } & Liking & 0.277 & $0.211,0.342$ & $0 \cdot 108$ & $0.077,0.139$ & $29 \cdot 5$ & & \\
\hline & Self-efficacy & $0 \cdot 167$ & $0.113,0.222$ & 0.082 & $0.053,0.112$ & $22 \cdot 6$ & & \\
\hline & Liking and self-efficacy & & & $0 \cdot 190$ & $0 \cdot 156,0.224$ & $52 \cdot 0$ & $0 \cdot 175$ & $0 \cdot 102,0.248$ \\
\hline \multirow{5}{*}{ Belgium } & Attitude & 0.074 & $0.018,0.129$ & 0.015 & $0.003,0.028$ & $6 \cdot 0$ & & \\
\hline & Liking & 0.236 & $0.172,0.300$ & 0.072 & $0.048,0.095$ & $27 \cdot 8$ & & \\
\hline & Self-efficacy & $0 \cdot 119$ & $0.070,0.168$ & 0.047 & $0.026,0.069$ & $18 \cdot 4$ & & \\
\hline & Perceived barriers & -0.103 & $-0.164,-0.043$ & 0.029 & $0.011,0.048$ & $11 \cdot 5$ & & \\
\hline & Attitude, liking, self-efficacy and perceived barriers & & & $0 \cdot 164$ & $0.067,0.260$ & $63 \cdot 7$ & 0.093 & $0.033,0.153$ \\
\hline \multirow[t]{5}{*}{ Total } & Attitude & -0.065 & $0.044,0.085$ & 0.018 & $0.012,0.024$ & $6 \cdot 0$ & & \\
\hline & Liking & 0.240 & $0.216,0.264$ & 0.085 & $0.075,0.095$ & $27 \cdot 7$ & & \\
\hline & Self-efficacy & 0.155 & $0 \cdot 137,0 \cdot 173$ & 0.061 & $0.053,0.069$ & $19 \cdot 9$ & & \\
\hline & Perceived barriers & -0.058 & $-0.078,-0.038$ & 0.016 & $0.010,0.022$ & $5 \cdot 3$ & & \\
\hline & Attitude, liking, self-efficacy and perceived barriers & & & $0 \cdot 180$ & $0 \cdot 169,0 \cdot 191$ & $58 \cdot 8$ & $0 \cdot 126$ & $0.284,0.331$ \\
\hline
\end{tabular}






sample, it seems that school availability is associated with fruit intake mediated by three mediating variables but is not directly associated with fruit intake. Since the observed overall relationships between school availability of fruit and fruit intake and the mediating pathways of this association differ across countries, this association and its underlying mechanisms are probably highly influenced by country differences in sociocultural environments and/or school environmental factors. Furthermore, it may also be that potential moderating variables play a role and that an association between school availability and fruit intake is only present in specific subsamples of the population. For instance, whether or not children bring fruit from home to school may have a moderating role. This was outside the scope of the present study, but needs to be explored in future studies.

That we did not find associations between school availability and fruit intake in most countries may be partly due to the so-called suppression effects by mediators included in the present study. This phenomenon has been described previously, and is present when mediated and direct effects have opposite signs. It also results in very high proportions of the total effect mediated. However, in the present study, the direct effects were not significant and very close to zero. Furthermore, MacKinnon et al.'s ${ }^{(33)}$ suggestions for the interpretation of the third-variable effects say that in case of positive thirdvariable effects (i.e. positive mediation effects), direct effects (close to zero) and overall effects greater than the direct effects $\left(c>c^{\prime}\right)$, there is no evidence for mediation, confounding or suppression. Therefore, the findings for the mediation analyses for the relationship between school availability and fruit intake in the Spanish, Danish and Austrian samples should not be used, as they are derived from inconsistent mediation models ${ }^{(33)}$.

Reinaerts et $a l^{(34)}$ did find that habit was an important factor related to fruit intake, although they also concluded that availability and taste preferences should not be ignored. Other studies also showed that home availability and taste preferences are among the strongest factors that are related



Although availability of fruit has been found to be an important predictor of intake, it is just one type of environmental factor. Swinburn et al. $^{(37)}$ have conceptualized four different types of environment, i.e. physical (what is available), economic (what are the costs), political (what are the 'rules') and socio-cultural (what are the attitudes and beliefs). Therefore, similar mediation analyses using other environmental factors than availability, such as school food policies or costs of fruit, can be recommended.

In addition, children may bring fruit to school themselves, and thereby affect the availability of fruit during the school day. For some of the countries included in the present study, it is quite common that the children themselves bring fruit to school. In Austria, Denmark, Iceland, Norway and Sweden, more than one-third of 
children said that they brought fruit to school on all or most school days (SJ te Velde, unpublished results). Such information has not been included in the measure of child-reported school fruit availability in the present study, and may have contributed to the low association between fruit availability at school and fruit intake.

Home and school availability of fruit was self-reported and thereby a measure of perceived availability, rather than an objective measure. However, children's perception of the environment might be more important in determining the mediated route of environmental influences on behaviour ${ }^{(23)}$.

Some limitations of the present study should be mentioned. Owing to the cross-sectional design of the study, no conclusions can be drawn about causality or prediction. It is possible that attitude, preferences, self-efficacy and barriers influence home availability and this in turn influences fruit intake, so that home availability is considered as a mediating variable or that intake influences the presumed mediators and determinants. Further, longitudinal research should explore predictive associations between these factors. In order to assess the effects of mediators, longitudinal data would be more appropriate, as has been done by Bere $e t a l .{ }^{(38)}$. Another limitation is the assessment of intake and its potential-related factors by just a few selfreported items. We used data from the larger Pro Children study, in which a broad range of potential intake-related factors, and therefore only a few items per factor or singleitem constructs were included. The questionnaire has, however, been validated before the study. However, the reliability of the scales were generally low, which impairs the ability to detect relationships. Finally, the participation rate of schools was rather low in some countries. Unfortunately, participation bias at the school level cannot be tested. Participation bias at the child level was caused by being present or not on the day of the data collection. All children who were present in the classroom participated in the study, and not being present was not a conscious decision of the children.

Multi-collinearity, i.e. strong correlations between the potential mediators, may have affected the multiple mediator analyses. However, inter-correlations between all mediators were below 0.60 (SJ te Velde, unpublished results).

The strengths of the present study were the validated instrument to assess intake and potential psychosocial and environmental related factors and the rather high response rates, although the participation rate at the school level was low in some countries, which might have introduced bias. Large, and in most cases representative, sample sizes from nine different European countries and applying mediation analyses while taking the nested design into account can be seen as the other strengths of the present study. Furthermore, the results of the study contribute to our understanding of the relationship between home or school availability of fruit and fruit intake among primary-school children.

\section{Conclusions}

The present study showed that liking and self-efficacy for eating fruit were the strongest mediators in the relationship between home availability as well as school availability of fruit and self-reported fruit intake among 11-year-olds. Home availability also showed a direct association with fruit intake. This is an indication that home availability of fruit may be a determinant to target in interventions promoting fruit intake among adolescents. Future research should include more reliable measures, a broader range of environmental factors and use longitudinal or experimental designs to further study the explored relationships.

\section{Acknowledgements}

Sources of funding: The present study was supported by the Commission of the European Communities' specific RTD programme 'Quality of Life and Management of Living Resources, (Grant no. QLK1-2001-00547), 'Promoting and Sustaining Health through Increased Vegetable and Fruit Consumption among European Schoolchildren' (Pro Children), and has been facilitated by the EU-funded HOPE project: 'Health-promotion through Obesity Prevention across Europe (the Commission of the European Communities (Grant no. SP5ACT-2006-044128)). The study does not necessarily reflect the Commission's views and in no way anticipates the Commission's future policy in this area. The study carried out by S.J.t.V. is supported by the World Cancer Research Fund (Grant no. 2007/47). Conflict of interest declaration: None of the authors had any conflict of interest. Authorship responsibilities: M.W. participated in the data collection, wrote the manuscript and incorporated inputs from all other authors in the manuscript. S.J.t.V. performed the statistical analysis and provided critical comments on the manuscript. J.B. and K.-I.K. participated in designing the study and project planning. C.S. participated in the data collection. All authors have read and approved the final version of the manuscript.

\section{References}

1. Yngve A, Wolf A, Poortvliet E et al. (2005) Fruit and vegetable intake in a sample of 11 -year-old children in 9 European Countries: the Pro Children cross-sectional survey. Ann Nutr Metab 49, 236-245.

2. Vereecken CA, De Henauw S \& Maes L (2005) Adolescents' food habits: results of the health behaviour in school-aged children survey. Br J Nutr 94, 423-431.

3. Larson NI, Neumark-Sztainer D, Hannan PJ et al. (2007) Trends in adolescent fruit and vegetable consumption, 1999-2004: Project EAT. Am J Prev Med 32, 147-150.

4. Vereecken C \& Maes L (2000) Eating habits, dental care and dieting. In Health and Health Behaviour among Young People, pp. 83-95 [C Currie, K Hurrelman, R Settertobulte, R Smith, J Todd, editors]. Copenhagen: WHO. 
5. Johnson B \& Hackett AF (2007) Trends in fruit, vegetable and salad intakes in 9-10-year-old schoolchildren living in Liverpool, 2000-2005. Public Health Nutr 10, 252-255.

6. Van Duyn MS \& Pivonka E (2000) Overview of the health benefits of fruit and vegetable consumption for the dietetics professional: selected literature. J Am Diet Assoc 100, 1511-1521.

7. Bes-Rastrollo M, Martinez-Gonzalez MA, Sanchez-Villegas A et al. (2006) Association of fiber intake and fruit/ vegetable consumption with weight gain in a Mediterranean population. Nutrition 22, 504-511.

8. World Cancer Research Fund/American Institute for Cancer Research (2007) Food Nutrition, Physical Activity, and the Prevention of Cancer: a Global Perspective. Washington, DC: AICR.

9. Newby PK (2009) Plant foods and plant-based diets: protective against childhood obesity? Am J Clin Nutr 89, 1572S-1587S.

10. World Health Organization/Food and Agricultural Organization (2003) Diet, Nutrition and the Prevention of Chronic Diseases. WHO Report no. 916. Geneva: WHO.

11. Kelder SH, Perry CL, Klepp KI et al. (1994) Longitudinal tracking of adolescent smoking, physical activity, and food choice behaviors. Am J Public Health 84, 1121-1126.

12. Lien N, Lytle LA \& Klepp KI (2001) Stability in consumption of fruit, vegetables, and sugary foods in a cohort from age 14 to age 21. Prev Med 33, 217-226.

13. te Velde SJ, Twisk JW \& Brug J (2007) Tracking of fruit and vegetable consumption from adolescence into adulthood and its longitudinal association with overweight. $\mathrm{BrJ} \mathrm{Nutr}$ 98, 431-438.

14. Mikkila V, Rasanen L, Raitakari OT et al. (2004) Longitudinal changes in diet from childhood into adulthood with respect to risk of cardiovascular diseases: The Cardiovascular Risk in Young Finns study. Eur J Clin Nutr 58, 1038-1045.

15. Baranowski T, Cullen KW, Nicklas $T$ et al. (2003) Are current health behavioral change models helpful in guiding prevention of weight gain efforts? Obes Res 11, Suppl., S23-S43.

16. Brug J, Oenema A \& Ferreira I (2005) Theory, evidence and Intervention Mapping to improve behavior nutrition and physical activity interventions. Int J Behav Nutr Phys Act 2, 2.

17. Cullen KW, Baranowski T, Owens E et al. (2003) Availability, accessibility, and preferences for fruit, 100\% fruit juice, and vegetables influence children's dietary behavior. Health Educ Behav 30, 615-626.

18. Kratt P, Reynolds K \& Shewchuk R (2000) The role of availability as a moderator of family fruit and vegetable consumption. Health Educ Behav 27, 471-482.

19. Young EM, Fors SW \& Hayes DM (2004) Associations between perceived parent behaviors and middle school student fruit and vegetable consumption. J Nutr Educ Behav 36, 2-8.

20. Jago R, Baranowski T \& Baranowski JC (2007) Fruit and vegetable availability: a micro environmental mediating variable? Public Health Nutr 10, 681-689.

21. Sallis S \& Owen N (2002) Ecological models of health behavior. In Health Behavior and Health Education: Theory, Research, and Practice, pp. 153-165 [K Glanz, B Rimer and F Lewis, editors]. San Fransisco: Jossey-Bass.
22. Booth SL, Sallis JF, Ritenbaugh C et al. (2001) Environmental and societal factors affect food choice and physical activity: rationale, influences, and leverage points. Nutr Rev 59, S21-S39.

23. Kremers SP, de Bruijn GJ, Visscher TL et al. (2006) Environmental influences on energy balance-related behaviors: a dual-process view. Int J Behav Nutr Phys Act 3, 9.

24. Bargh JA \& Chartrand TL (1999) The unbearable automaticity of being. Am Psychol 54, 462-479.

25. Klepp KI, Pérez-Rodrigo C, De Bourdeaudhuij I et al. (2005) Promoting fruit and vegetable consumption among European schoolchildren: rationale, conceptualization and design of the Pro Children project. Ann Nutr Metab 49, 212-220.

26. Rasmussen M, Krolner R, Klepp KI et al. (2006) Determinants of fruit and vegetable consumption among children and adolescents: a review of the literature. Part I: quantitative studies. Int J Behav Nutr Phys Act 3, 22.

27. Wind M, Bobelijn K, De Bourdeaudhuij I et al. (2005) A qualitative exploration of determinants of fruit and vegetable intake among 10- and 11-year-old schoolchildren in the low countries. Ann Nutr Metab 49, 228-235.

28. Haraldsdóttir J, Thórsdóttir I, de Almeida MDV et al. (2005) Validity and reproducibility of a precoded questionnaire to assess fruit and vegetable intake in European 11- to 12year-old schoolchildren. Ann Nutr Metab 49, 221-227.

29. De Bourdeaudhuij I, Klepp KI, Due P et al. (2005) Reliability and validity of a questionnaire to measure personal, social and environmental correlates of fruit and vegetable intake in 10-11-year-old children in five European countries. Public Health Nutr 8, 189-200.

30. MacKinnon DP (2008) Introduction to Statistical Mediation Analysis. New York, NY: Lawrence Erlbaum Associates.

31. Cerin E \& MacKinnon DP (2008) A commentary on current practice in mediating variable analyses in behavioural nutrition and physical activity. Public Health Nutr 12, 1-7.

32. Blanchette L \& Brug J (2005) Determinants of fruit and vegetable consumption among 6-12-year-old children and effective interventions to increase consumption. J Hum Nutr Diet 18, 431-443.

33. MacKinnon DP, Krull JL \& Lockwood CM (2000) Equivalence of the mediation, confounding and suppression effect. Prev Sci 1, 173-181.

34. Reinaerts E, de Nooijer J, Candel M et al. (2007) Explaining school children's fruit and vegetable consumption: the contributions of availability, accessibility, exposure, parental consumption and habit in addition to psychosocial factors. Appetite 48, 248-258.

35. Brug J, Tak NI, te Velde SJ et al. (2008) Taste preferences, liking and other factors related to fruit and vegetable intakes among schoolchildren: results from observational studies. Br J Nutr 99, Suppl. 1, S7-S14.

36. Gallaway MS, Jago R, Baranowski $\mathrm{T}$ et al. (2007) Psychosocial and demographic predictors of fruit, juice and vegetable consumption among 11-14-year-old Boy Scouts. Public Health Nutr 10, 1508-1514.

37. Swinburn B, Egger G \& Raza F (1999) Dissecting obesogenic environments: the development and application of a framework for identifying and prioritizing environmental interventions for obesity. Prev Med 29, 563-570.

38. Bere E, Brug J \& Klepp KI (2008) Why do boys eat less fruit and vegetables than girls? Public Health Nutr 11, 321-325. 